\title{
DiGITALCOMMONS
}

@WAYNESTATE-

Criticism

Volume 63 | Issue 4

Article 6

2021

\section{A Field in Formation: Intersectionality is/as Social Justice}

Lee Y. Weeks Jr.

Follow this and additional works at: https://digitalcommons.wayne.edu/criticism

\section{Recommended Citation}

Weeks, Lee Y. Jr. (2021) "A Field in Formation: Intersectionality is/as Social Justice," Criticism: Vol. 63 : Iss. 4 , Article 6.

Available at: https://digitalcommons.wayne.edu/criticism/vol63/iss4/6 
A FIELD IN

FORMATION:

INTERSEC-

TIONALITY IS/AS

SOCIAL JUSTICE

Lee Y. Weeks Jr.

A review of Intersectionality as Critical Social Theory by Patricia Hill Collins. Durham, NC: Duke University Press, 2019.376 pp. $\$ 109.95$ cloth, $\$ 29.95$ paper.
Social theory in and of itself can be a daunting scholarly enterprisenot least when framed within and through critical positionalities. While intersectionality at first glance may seem to be a relatively approachable social theory, especially given its increasing popularity in scholarly and popular modalities, it has proven to be substantively rich, complex, and consequential. In Intersectionality as Critical Social Theory, Patricia Hill Collins, preeminent scholar of intersectionality, takes on the ambitious project of positioning intersectionality as a critical social theory and illuminating the productive possibilities for intersectionality both epistemologically and methodologically, especially as a social justice project. By positioning intersectionality, Collins simultaneously contextualizes critical social theory and charts critical social theory's potential for scholars invested in activism and social justice who might otherwise be located in fields that self-identify and/or are identified as critical.

Collins politically situates and consequently politicizes intersectionality. Rather than catering to the academy's impetus to privilege so-called objective knowledge, Collins argues that critical social theory and concurrently intersectionality can only be critical insofar as their ethical commitments to social justice. Knowledge operating under the guise of neutral objectivity not only gets conferred 
with academic capital and epistemic power, but has historically proven to be an insidious weapon readily appropriated towards unjust, illiberal ends. In chapter 8, Collins specifically traces how eugenics, which she reads as a misguided project of intersectionality, forecasts the danger of not declaring ethical commitments. Said differently, intentions matter, and those intentions need to be deliberate and precise, not because our intentions guarantee the ends, but because the refusal to position our projects accrues unnecessary, undue risk.

Organizationally, Intersectionality as Critical Social Theory is divided into four parts comprised of two chapters each. Part I, "Framing the Issues: Intersectionality and Critical Social Theory," defines the essential contours of intersectionality and its relationship with established critical social theories. Part II, "How Power Matters-Intersectionality and Intellectual Resistance," identifies various strategies of intellectual resistance by locating intersectionality where critical social theory substantiates its critical capacity. Part III, "Theorizing IntersectionalitySocial Action as a Way of Knowing," considers intersectionality's methodology: specifically, Collins argues that dialogical engagement and building "inclusive communities of inquiry" are the cornerstones of intersectionality's methodology (15). Finally, Part IV, "Sharpening Intersectionality's Critical Edge," serves as Collins's estimation of what will be most imperative for scholars of intersectionality to practice in order for intersectionality to meet its promise to be a critical social theory. Namely, intersectionality's critical edge and relevance are best fostered by a commitment to social justice.

Chapter 1, "Intersectionality as Critical Inquiry," assesses how scholars of intersectionality practice intersectionality in their projects-as metaphor, heuristic, and paradigm. In addition, Collins charts the tensions between intersectionality's modalities in both the social sciences and the humanities. Broadly, projects in the social sciences theorize social truth while humanities search for social meaning; Collins argues that intersectionality can and should attend to both. To that end, Collins argues that theory should "explain a given social phenomenon, not simply describe it" (51). Therefore, "intersectional theorizing would be the process or methodology used in developing those explanations" (51, her emphasis).

In Chapter 2, "What's Critical about Critical Social Theory?" Collins reviews critical social theory in the academy and charts how intersectionality might fit and (critically) intervene. "Critical," Collins notes, is often taken for granted as a certain kind of departure from or intervention within traditional social theories. Collins evaluates major established critical theories, 
specifically the Frankfurt School, British Cultural Studies, and Francophone Social Theory. This chapter offers a helpful introductory guide for those who might be newly navigating critical social theory and Cultural Studies; Collins both appreciates the contributions these fields have made while also accounting for their missteps and missed opportunities. Her critiques use an intersectional analytic that challenges reformist and transformative teleologies. She ultimately concludes that the reformist or transformative potential for any given theory hinges on its dialogical engagement with other social theories in their respective research and political contexts.

Intersectionality's dialogical engagement with other social theories is considered in chapter 4, where Collins locates critical race theory, feminist politics and theory, and postcolonial and decolonial theories as sites that resonate intersectionally and wherein intersectionality might model its own praxis. Collins explicates how intersectionality can and should intervene in epistemic power and epistemic violence through praxes of epistemic resistance: "dialogical engagement is not just a theoretical idea. It is a methodological process" that ultimately requires intersectionality to dialogically engage with other theories and especially selfreflexively (146).

The sites from whence ideas emerge have significant implications and consequences for social theories and their entrenched (re)productions of epistemology. In chapter 5, Collins provides Ida B. Wells as paradigmatic: lived experience read as narratives of resistance informs the praxis of a (culturally contingent) community, in this case black feminist thought and politics. Chapter 6 compares Simone de Beauvoir and Pauli Murray. Collins finds that Murray's theory grounded her activism and commitment to social justice that optimally positioned her with the communities she was supporting. Beauvoir, on the other hand, depends on traditional social theory, which in a move of hubris casts her partial experience as a grand ontological theory of freedom for all. Freedom then may be best theorized not as a substantive end but better approached pragmatically in situated contexts that necessarily requires intersectional depth (221).

Collins models relational, intersectional thinking throughout the text, and addresses this conjunction specifically in chapter 7 . She finds three modes of relational inquiry: additive, articulation, and co-formation. Additive frameworks reveal how adding categories of analysis essentially changes the perspective of an argument while simultaneously changing prior axes of analysis to account for intersectional nuance. Said differently, it is worth paying attention to how adding categories impacts preexisting categories of analysis. Building 
on Stuart Hall's theory of articulation, Collins argues that articulation "provides a framework for the changing relationships among multiple systems of power" (233). Society is not one organic totality but instead comprised of multiple parts, wherein systems of power connect or are articulated in contextually specific ways with no predictable or fixed outcomes. Therefore, articulation attends to the intimacies among ideas, as well as between ideas and society, rather than addressing them in (incomplete) fragments. Co-formation proves to be the most challenging relational form to decipher; at the center of this argument is a postmodern position that understands categories to be socially contingent and not essentially fixed. What we understand to be categories in a moment are always already coforming, all mutually constitutive and intelligible in such a way that their fixed boundaries are merely an illusion of a particular cultural moment. To approach co-formation is to attend to difference(s) with an acknowledgment of their simultaneity, as always already embedded, a part of, and co-formed together.

As it might be apparent from the chapter summaries, this text ambitiously investigates intersectionality and critical social theories with urgent concern over the longterm development of the field as a critical social theory. Rather than offering prescriptive formulas, Collins diagnoses intersectionality and critical social theories as they have been used in scholarly discourse-which is in and of itself indicative of intersectionality's field formation in its own right. As a cornerstone of intersectionality, Collins insists on an ethical commitment to social justice, not only as an end but also as core methodology and praxis. While Collins does not delimit the specific boundaries of such an ethical commitment, her observations on past mistakes made in critical social theories and the illiberal deployment of intersectionality within eugenics serve as a provocative warning for intersectional scholars to be attentive to not only the implications of their work but also the future that their work faces.

Intersectionality as Critical Social Theory is accessibly written, but the ideas as Collins covers them are complex and consequently may require a more attentive, reflective, and longer read. This book will be particularly useful for scholars interested in intersectionality, critical social theories, and those scholar activists invested in scholarship of and as social justice.

Lee is a PhD student in the Department of Gender Studies at Indiana University. He is interested in the constructions of the abject, particularly in the configurations of (other) localized intersecting identities such as race, class, sexuality, and gender that make the abject possible and socially malleable. 